\title{
ERP in Higher Education: A Case Study of SAP and Campus Management
}

\author{
Mary Jo Davis, BIS Department, Central Michigan University, davis1mj@cmich.edu \\ Zhenyu Huang, BIS Department, Central Michigan University, $\underline{\text { huang1z@cmich.edu }}$
}

\begin{abstract}
Enterprise Resource Planning (ERP) software has been applied to industries to support financial accounting, procurement, human resources, customer service management and supply change management. Recently, it is being promoted to new areas, for example, higher education. This case study examines the application of ERP software to the student information management in higher education at a Midwestern university that has replaced its legacy software with an ERP system. This paper also explores critical success factors (CSF) for a successful ERP implementation discussed in the literature. In addition, this paper investigates user acceptance of this new system specifically examining the staff attitudes, concerns expressed and comfort level for the average user.
\end{abstract}

Keywords: ERP, Higher Education, Campus Management, Case Study

\section{INTRODUCTION}

In order to maximize profits and improve data management, businesses have been converting their record keeping software to Enterprise Resource Planning (ERP) systems. Available ERP options have provided business with modules to integrate their human resource, financial, manufacturing, customer service, and other units, all using a common interface and one common communication language. Billions of dollars have been spent on these new enterprise systems in the last decade, all of which were intended to improve record keeping, data accuracy, security, and streamline operations [1]. The process of evaluating an ERP system for use in business requires that an organization compare the existing ERP software available to their current business processes and see which ERP will best fit the existing business procedures. While no EPR will be a perfect fit, the less customization required to match the ERP to the business will insure a better operating ERP software for the business.

Many critical success factors (CSF) can influence the success or failure of any ERP implementation. In this case study, key questions to be examined will be formulated on the CSF identified in current literature. Of these success factors, the following questions will be answered:

1. What research, preparations and timeline for implementation should an institution of higher learning undertake to insure success?

2. Has the subject of this case study followed the guidelines and best practices identified in current literature for their implementation?

3. How satisfied and comfortable are current staff members with the new software and how could their satisfaction level affect the success of this ERP implementation?

This case study will begin with a literature review including an examination of the history of ERP software development and application of this type of software to the "business" of higher education. Next will be a discussion of the literature written regarding the "fits and misfits" of ERP business software as a solution for higher education. Following this will be a discussion of CSF that influence the success or failure of an ERP implementation project in addition to the best practices identified in the industry. Finally these CSF and best practices will be used as a guide to review the preparation and process followed during implementation of the Campus Management software at a medium-sized research-intensive Midwest university. This study is designed to fill gaps in current research by providing a case study of an implementation of ERP in higher education, measuring the success of this implementation, and discussing the steps and processes followed.

\section{LITERATURE REVIEW}

In the years leading up to the new millennium, business and industry began to realize they had a huge problem on their hands: Y2K. Research discussing the anticipated $\mathrm{Y} 2 \mathrm{~K}$ crash and efforts to forego any data loss highlights how many companies investigated new data management software to replace their outdated legacy systems before January 1, 2000 [10]. This new software need led to the market growth for ERP software, designed to replace legacy systems and envelope all facets of a business under one software "umbrella." As new modules 
were developed and new uses found for the different capabilities of ERP software, companies invested millions of dollars into these new systems, hoping to gain a competitive edge [6].

ERP vendors are now exploring new markets by promoting business software to higher education as a solution to their data management needs. It is expected that higher education's collective investment in vendor-supplied enterprise administrative systems, modified versions of the standard ERP systems, may exceed $\$ 5$ billion to date, placing it "among the academy's most significant information technology (IT) investments of any kind" [8]. In order to accurately gather data regarding the use of ERP software in higher education, the EDUCAUSE Center for Applied Research (ECAR) conducted a qualitative and quantitative survey of institutions that completed an ERP implementation since 1995 and published the results of this research in the King study [8]. The budget for an ERP implementation can run into tens to hundreds of millions of dollars, with expenditures estimated to range between approximately $6 \%$ of their annual revenue for a large organization to up to $50 \%$ for small firms. In addition, as implementation costs rise, so does the chance of an implementation failure [1].

Research into ERP implementations in the "business" of education has focused mainly on how to research and choose ERP software [12] and how the university differs from traditional businesses that employ a traditional ERP system [13]. There is a case study discussing an ERP implementation at another Midwestern university between 1997 and 2003 [3] but few case studies have been published for recent ERP implementations on campuses.

Research regarding the success of fitting ERP software to existing business practices is also applicable to the literature review for this case study. Cases discussing failures of ERP implementations and the factors causing those failures have been documented by Barker \& Frolick [2] and Grossman and Walsh [7]. In one case study where an ERP implementation was unsuccessful, Barker discusses the chances of failure and factors that could insure success "With all these things in mind and considering that well over half of all ERP implementation efforts end in failure, excellent planning, incorporating employee involvement, and good communication should be at the top of any organization's list when considering an ERP implementation effort" [2]. Another factor for discussion is the need to adjust business practices or ERP software to fit the firm. The more an ERP system is modified to fit a business, the more the likelihood of implementation failure. Failure rates for ERP implementations are estimated to range between $50-90 \%$, depending upon the research used [5]. It is recommended that businesses/organizations minimize their customization of the ERP software and employ more Business Process Reengineering (BPR) to the implementation process to improve their chance for success [11]. Other research conducted into ERP implementations discusses the recommended process for a successful ERP selection [17] and ten critical success factors for success [16].

\section{RESEARCH METHODOLOGY}

This research project was conducted using a survey instrument administered online in Survey Monkey. Staff, supervisory employees and Campus Management (CM) employees were contacted via email inviting them to participate in the survey and providing them with a link to the survey website. Survey results will measure the perceived acceptance of the new system and what user factors affect a successful implementation. Also, this case will compare the CSF and best practices found in current research that have been found to improve the chance of a successful ERP implementation.

The process of identifying a sample to survey involved identification of key staff members who were impacted by the CM implementation because their daily work was affected by this implementation. Groups identified to be invited to participate in this survey process include:

1. University, college and departmental leaders

2. Key support staff members in these offices

3. Campus staff that use the new CM system in their daily work

4. CM implementation team members

A web site was created to inform the university community about the progress of the CM implementation Due to restrictions placed on access to gather research from CM staff, CM group notes, minutes and reports have been downloaded from this site and will be examined to identify key processes and procedures followed by the implementation team. Additionally, white papers from industry sources will be used for background information along with traditional sources of professional journals and publications.

\section{UNIVERSITY ORGANIZATIONAL HISTORY}

Founded late in the $19^{\text {th }}$ century, the university 
studied has a current enrollment of nearly 28,000 students in both on and off-campus locations across the world. While this university has one of the oldest and largest off-campus programs, it is the on-campus students and staff who will be the subjects of this study. Six on-campus academic units focus on 200+ programs and are committed to providing the students with outstanding opportunities in teaching and research. Over 155,000 graduates of this university live around the world. In addition to convergence of the FI, HR and CM system, this university hopes to someday include their online students in the CM system and provide some connection software between the vendor software and their development processes/software [4].

\section{Planning and Preparation}

\section{History of the ERP conversion process}

This university upgraded their financial and human resource software in 1997 to newer ERP-type software. The transition to this new system, as with any change, was not the smoothest, but with the human resources and financial modules having been in service for nearly 10 years, these modules have been functioning well. The previous vendor choice became an influential factor in the decision making process for the new CM, since smooth integration of current and past data is critical with any new ERP implementation [1].

\section{Need for new ERP system identified and studied}

This university agreed in 1999 to work with the vendor to develop the new student system. Following the development and testing of this new system, the university shared feedback with the vendor to help the company with continued development of the new system. In 2001, the university chose to finalize a contract with the vendor to purchase the new Campus Management system. The decision to move ahead to the new ERP software package was explained to be necessary due to the fact that the current information system was antiquated and doesn't integrate well with website needs of current students as documented in studies by both Bajwa [1] and Vervilles \& Bernadas [16]. These activities fit into one of the CSF identified for a successful ERP project: extensive planning and preparation.

\section{Best Practices in Implementation}

The new student management system was to integrate all factions of the student data gathering needs and was to provide this new interface to students on a
24/7 real-time basis. Teams were established for the implementation project, with 10 core teams established in addition to the central team of seven members. These teams met on a regular basis to define the current business processes and how they will fit into the ERP system. The proceedings of the committee meetings were recorded and published to the CM website. By fall semester, two years into the project, core teams met on a monthly basis to discuss issues with data conversion and software needs. Some issues discussed were as simple as whether to have the name entries listed in all upper case or in title case (legacy student information system dealt with data in all capital letters) to discussion of the success and failures of sample data migrations. These processes can be considered to fit the one best practices needed for a successful implementation: teambuilding and communication.

According to historical documents on the project, the original go live date for the full functionality was January 2006. In actuality, the first semester go live date was for fall 2006, which took place in early July, 2006. Although this date was not too far off the initial projected date, this fact helps to reinforce the best practices/critical success factor finding that an ERP implementation project will be a time consuming project involving large groups of employees.

\section{Effective leadership is critical}

A new project manager was brought to the $\mathrm{CM}$ project in mid-2005. The addition of this new team member appeared to improve continuity of the overall project and the organizational function regarding project management. After reading the meeting notes and project reports for the CM project at this university, this person could be considered to be the team leader or project champion for the $\mathrm{CM}$ project at this university. This is an additional recommended CSF for a successful ERP implementation [11].

\section{Over Budget and Off the Timeline}

\section{Testing for effectiveness and a good fit}

Near the end of 2004 the university's CM teams were expanding in size. The final timeline was adjusted to accommodate the unscheduled delays in conversion testing and data validation. Issues were also discussed regarding the ability of existing hardware to handle both conversion processing and data testing. Some testing was postponed due to system slowdown for both the conversion servers and the live HR systems. Critical decisions had to be made 
early in 2005 regarding the CM project. It was discussed that with limited hardware systems and excess demand placed on IT personnel, non-critical IT projects may need to be put on hold until after CM go live in 2006. At this time it was approved by upper level management to focus on a features approach for phase in of the new system rather than full modules. This would allow for a limited start up of critical key functions rather than the complete system. Also, at this time the CM team decided to step back and review how the CM functionality fits together. This would provide “.... a foundation for a collaboration as we work together to reduce the current project plan so a Spring 2006 go live will be possible" [4]. This is another proof of the ERP implementation issue of new software implementations running over budget and missing the target implementation deadline [1, 9, 11, 16, 17].

\section{Fit it, don't break it}

An issue critical for success of an ERP implementation involves minimizing the customization done with the vendor's software package. It is believed that the more customization or work-around solutions that are designed for ERP software, the less successful an implementation may be [11]. In the case of this university, the disbursement of revenue (tuition) was a questionable issue. According to the vendor's schedule of business processes, this would traditionally be an HR function. Two optional solutions were available for this problem: one was to design a work-around by local IT specialists (at minimal cost) or have the vendor design a solution (at $\$ 20,000$ ). The CM committee decided to work on an internal solution, designed by the university's IT specialists, with guidance from another CM user. It is too early in the implementation to be able to determine the success or failure of this work-around [12].

During the process of data testing, additional software was purchased to facilitate data testing and to speed up the process. Expenditures have been noted in minutes for additional consultants, staffing and software. Data regarding the bottom line costs for these unanticipated needs has not been gathered, but would be worthwhile to provide a more accurate budgetary picture for this ERP implementation since 1999. Another issue to examine for total cost of this project would be to identify and compute the cost of the new and additional campus processes necessitated by this software conversion [5]. This factor would be additional proof of the tendency of ERP implementations running over budget and past deadline dates.

\section{The end is near, or is it?}

As the end of 2005 neared, the new project manager and the core teams had begun to categorize the issues reported into three categories: HIGH-a 'show stopper', MEDIUM: something the university would like to see up by go live date, or LOW: this issue can be resolved at a later date. Beginning in 2006, the countdown to both the testing deadline and go live deadline were posted regularly on project documents. All team members were advised to make their testing as thorough as possible and to test often. There were discussions about running servers systems simultaneously with other campus servers running the vendor software to see if multi-purpose process events would over-tax the network, hardware and software. Both repetitive data validation testing and load testing would help to increase the success of the implementation $[11,12]$.

By the time the new CM system at this university would go live in summer of 2006, seven years had passed since the initial discussion took place with upper management regarding vendor selection. This fits well in the theory that an ERP implementation is a long term process, exceeding the average of 1-3 years discussed in the article by Koch [9]. And it is too early in the history of this ERP implementation to determine the success or failure of the project. The system is running, but how much of the unused portions of the software are still in the testing phase is yet to be determined.

\section{Does the University Culture Understand and Accept CM?}

A survey was designed based on the CSF discovered during the literature review process. Questions were designed to measure the perception of average campus users toward the new Campus Management system and the affect these CSF had on the success of the Campus Management Project. A total of 211 survey requests were sent out via email to selected groups on campus. Response rates by group range from $0 \%$ to $36 \%$. Although the top survey percentage appears to be fairly good, the $36 \%$ is based on a small group of 11 participants. The highest response rate of any group from the 117 office professional and supervisory technical group contacted, at $21 \%$. With 36 total responses received, this group of average daily users provided $63.8 \%$ of the total responses received. These CM users are the "people in the trenches" who use the student information system daily to check section counts, student academic records and a myriad other data needed to complete their daily work assignments. At this time, these 
survey results will be the majority of the data analyzed.

Table 1: Were you a member of the Campus Management Team?

\begin{tabular}{|l|l|}
\hline & Response totals \\
\hline Yes & 2 \\
\hline No & 34 \\
\hline Total Responses & 36 \\
\hline Skipped question & 0 \\
\hline
\end{tabular}

As shown in the responses in Table 1, 94\% of the groups surveyed were not on any CM team. This is a concern in that few of the average daily users participated in any part of the business process analysis or data mapping procedures. This lack of participation in the implementation process could influence the group's acceptance of the new system and may contribute to the perception of lack of communication between management and staff. Also, this disconnect between the CM team and the average user could result in the staff feeling less of a commitment to the change to CM software.

Table 2: Impact/Effect of Specific Groups on Implementation Success

\begin{tabular}{|l|l|}
\hline Group & $\begin{array}{l}\text { Level of impact on success of } \\
\text { CM implementation }\end{array}$ \\
\hline Top management & $28 \%$-- had a high effect \\
\hline $\begin{array}{l}\text { Academic } \\
\text { administration }\end{array}$ & $\begin{array}{l}32 \% \text {--greater than average } \\
\text { effect }\end{array}$ \\
\hline $\begin{array}{l}\text { Financial } \\
\text { administration }\end{array}$ & $32 \%$--had some effect \\
\hline Human resources & $20 \%$--had no effect \\
\hline $\begin{array}{l}\text { Academic } \\
\text { departments }\end{array}$ & $28 \%$--had some effect \\
\hline $\begin{array}{l}\text { Their direct } \\
\text { supervisor }\end{array}$ & $32 \%$--had no effect \\
\hline
\end{tabular}

The results listed in Table 2 reflect the highest percentage of responses the average user's perceived had an impact on the success of the ERP implementation at the university studied. The largest impact is perceived to be in both the academic administration and financial administration departments. It should be noted that at the university studied, both the financial and human resource modules of software were first to be implemented, but the average user feels the human resource department had no impact on the implementation success. In addition, it should be noted that $32 \%$ of the average users perceived their direct supervisor had no effect on the system success. This factor could also negatively impact a sense of personal "buy-in" of this new CM system.
Table 3: Other issues affecting CM success

\begin{tabular}{|l|l|}
\hline Issue & $\begin{array}{l}\text { Affect on the success } \\
\text { of the CM system }\end{array}$ \\
\hline $\begin{array}{l}\text { I feel the CM program has } \\
\text { been well accepted by the } \\
\text { campus community }\end{array}$ & $\begin{array}{l}40 \% \text {-- some effect on } \\
\text { success of system }\end{array}$ \\
\hline $\begin{array}{l}\text { I feel the university } \\
\text { community was well } \\
\text { prepared for the CM } \\
\text { transition }\end{array}$ & $\begin{array}{l}31 \% \text {--greater than } \\
\text { average effect }\end{array}$ \\
\hline $\begin{array}{l}\text { The culture at this university } \\
\text { is exhibiting a positive } \\
\text { attitude toward the new CM } \\
\text { system }\end{array}$ & $\begin{array}{l}36 \% \text {--some effect on } \\
\text { project }\end{array}$ \\
\hline $\begin{array}{l}\text { The new system supports of the } \\
\text { the vision and business plan } \\
\text { of the university community }\end{array}$ & $\begin{array}{l}27 \% \text {--little effect on } \\
\text { success of the project }\end{array}$ \\
\hline $\begin{array}{l}\text { Teams working on the CM } \\
\text { project were well organized, } \\
\text { exhibited teamwork and } \\
\text { were effectively designed }\end{array}$ & $\begin{array}{l}31 \% \text {--had some } \\
\text { effect on the success } \\
\text { of the project }\end{array}$ \\
\hline $\begin{array}{l}\text { Communication was } \\
\text { effective and well managed } \\
\text { during the } \\
\text { implementation project }\end{array}$ & $\begin{array}{l}40 \% \text {--greater than } \\
\text { average effect on } \\
\text { success of the project }\end{array}$ \\
\hline
\end{tabular}

Looking at the results of this section, reflected in Table 3, the average user at this university does not appear to believe the CM software supports of the vision and business plan of the organization and is critical to the success of the new system, directly opposite of what is viewed as a CSF for implementation success. Table 3 also illustrates that communication is an important part of the success of the implementation process and preparedness has a greater than average effect on success of this implementation. Team make-up and organization was considered to have some effect on success while the average user felt that acceptance of the new system has some effect on the success of the implementation.

Table 4: Other pertinent CSF and the perception of the average user

\begin{tabular}{|l|l|}
\hline Critical Success Factor & $\begin{array}{l}\text { Do they influence } \\
\text { the success of this } \\
\text { implementation } \\
\text { project? }\end{array}$ \\
\hline $\begin{array}{l}\text { Communication was } \\
\text { effectively maintained during } \\
\text { this CM project at this } \\
\text { university. }\end{array}$ & $35 \%$--some effect \\
\hline $\begin{array}{l}\text { Training was scheduled and } \\
\text { held effectively for } \\
\text { employees at this university } \\
\text { for the new CM system. }\end{array}$ & $\begin{array}{l}\text { greater than average } \\
\text { effect }\end{array}$ \\
\hline
\end{tabular}




\begin{tabular}{|l|l|}
\hline $\begin{array}{l}\text { Training materials were well } \\
\text { designed for employees at } \\
\text { this university for the new } \\
\text { CM system. }\end{array}$ & $25 \%$--some effect \\
\hline $\begin{array}{l}\text { Training at this university } \\
\text { increased the effectiveness of } \\
\text { employees using the new CM } \\
\text { system. }\end{array}$ & $\begin{array}{l}25 \% \text {--split equally } \\
\text { between no effect, } \\
\text { little effect and some } \\
\text { effect }\end{array}$ \\
\hline $\begin{array}{l}\text { Telephone assistance and } \\
\text { help desk operations were } \\
\text { well planned and are easily } \\
\text { accessible at this university } \\
\text { for the new CM system. }\end{array}$ & $\begin{array}{l}\text { some effect and and } \\
\text { greater than average }\end{array}$ \\
\hline
\end{tabular}

Two key CSF identified for any ERP implementation involve both effective communication and training. At the university studied, 35\% of the test group felt effective communication had some effect on project success. And when training was questioned none of the three questions identified well designed, effective training was more than having some effect on the success of the project. Only $25 \%$ felt that the training was helpful and was scheduled and held as needed. One last area discussed was the on-campus support provided by the university. The test group rated the help desk and telephone assistance available on campus at $25 \%$ for both having some effect and a greater than average effect on the success of the $\mathrm{CM}$ implementation.

Lastly, the participants in this survey were encouraged to include additional comments regarding their perceptions of the $\mathrm{CM}$ implementation. The following are quotes from those comments:

- "I am not impressed with the new CM system. Fortunately, I have a wonderful, knowledgeable supervisor who I can go to with all of my questions. Unfortunately, this new system has slowed the process of my job considerably."

- "I feel most of the core teams did their work, but some did not and this caused other teams to be unable to test job steps they do regularly in serving our student population.”

- "Training was non-existent. The testing and development phase was poorly planned. No one asked us what reports we needed to remain operational and they are still not done."

- "The legacy system was cut off too soon. Many reports ... not yet available and getting the information needed is not a simple matter anymore."

- "The system was implemented prior to it being ready. Many of the screens needed by departments were not ready, have been created with multiple ludicrous steps in order to access information (one screen, I now have 5 different steps in order to access information instead of 1 in the old system."

- "The system was put in production too early. Many reports that were identified as needed for go live are still not available."

- "We still encounter numerous problems with $\mathrm{CM}$. We have emailed and phoned in our needs which are still unresolved."

- "I think once the "kinks" are worked out it'll be an effective system. Right now too many things are not accessible (campus addresses \& phone numbers, reports, etc.).”

\section{CONCLUSIONS}

1. Through the process of studying the historical records of this ERP implementation project and reviewing the results of the survey of current staff members, several conclusions can be drawn. The records studied revealed that this Midwestern university put several years of research and preparation into the transition process from the legacy system. Over two years of research took place prior to the vendor choice, with some of the preference of vendor based on a successful transition to the vendor's financial and HR modules. Time spent scrutinizing the current student management system and how the business processes are transacted allowed for effective business process restructuring to fit the new ERP. Following data migration trials, the data was tested and retested insuring the new system would function as needed. And although the final "go live" date did not see all of the planned modules brought online, the project proceeded as expected in current research, with some budget and time frame over-runs. Once the new project manager was brought to the project, the teams refocused their energies to bring the new ERP system into use only six months later than originally planned.

When it comes to user satisfaction, current literature finds that some user dissatisfaction is to be expected, and this is the same at this Midwestern university. The survey responses revealed concern among the regular users regarding the effectiveness of the new ERP, if the new system has improved their work processes and if they have had adequate support and training. Study of CSF has also revealed that user satisfaction is a critical part of the success of an ERP implementation. It is too early to determine whether user satisfaction will negatively influence this ERP implementation or not. More study will need to be done in the future to prove or disprove this theory. 


\section{LIMITATIONS}

This case study of an ERP implementation at this medium sized Midwest university has been designed to gather an overall view from the perspective of staff, team members and in the future, gathering and interpreting student opinions. Recent literature has been reviewed to see the key theories, critical success factors and best practices currently recognized in the industry to insure a successful ERP implementation, in this case in a university environment. Survey tools have been designed and sample populations randomly selected to be surveyed at some of all the academic and administrative offices at this university. While the goal of the initial research proposal was effectively designed, the result of this first draft of the research paper is not an example of effective research due to of the limited access allowed to the CM team members and the limited number of survey responses. Both additional access to university team members and increased survey participation will improve the validity of a future case study. If these contacts can be established and adequate survey responses gathered, this case study will add valuable information to the body of knowledge of ERP software industry for use by institutions of higher educational contemplating upgrading their management software in the future.

\section{REFERENCES}

2. Bajwa, D. S., Garcia, J. E. \& Mooney, T. (2004). An Integrative Framework for the Assimilation Enterprise Resource Planning Systems: Phases, Antecedents, and Outcomes. The Journal of Computer Information Systems, 44(3), 81-90.

3. Barker, T., \& Frolick, M. N. (2003). ERP Implementation Failure: A Case Study. Information Systems Management, 20(4), 42-49.

4. Borchers, A. (2004) Wiring Watkins University: Does IT Really Matter? Journal of Electronic Commerce in Organizations, 2(4), 30-46.

5. Campus Connections at Central Michigan University. Accessed on October 8, 2006 at http://www.sap.cmich.edu/cm/default.asp.

6. Chen, I.J. (2001). Planning for ERP systems: analysis and future trend. Business Process Management Journal, 7(5), 374-386.
7. Cotran, K., Buchmeister, U., Sequin, J. L., \& Pelster, B. (2005). HR's role in implementing JTI's global ERP system. Strategic HR Review, 4(5), 24-27.

8. Grossman, T. and Walsh, J. (2004). Avoiding the Pitfalls of ERP System Implementation. Information Systems Management, 21(2), 38-42.

9. King, P., Kvavik, R. B. \& Voloudakis, J. (2002). Research Bulletin: Enterprise Resource Planning Systems in Higher Education. Boulder, CO: ECAR (Educause Center for Applied Research).

10. Koch, C. (2002). The ABC's of ERP, CIO ERP Research Center. Accessed on November 25, 2005 at http://www.cio.com/research/erp/

11. edit/erpbasics.html.

12. Lally, L. (2005). Information Technology as a Target and Shield in the Post 9/11 Environment. Information Resources Management Journal, 18(1), 14-29.

13. Nah, F.; Lau, J. \& Kuang, J. (2001) Critical Factors for Successful Implementation of Enterprise Systems. Business Process Management Journal, 7 (3), 285-296.

14. Okunoye, A.; Frolick, M. \& Crable, E. (2006, April/June). ERP Implementation in Higher Education: An Account of Pre-Implementation and Implementation Phases. Journal of Cases on Information Technology, 8(2), 110-132.

15. Pollock, N. \& Cornford, J. (2004). ERP Systems and the University as a "Unique" Organisation. Information Technology \& People, 17(1)., 31.

16. SAP Campus Management. 2005. Accessed October 25, 2006. http://www.sap.com/

17. industries/highered/brochures/index.epx

18. Umble, E., Haft, R., \& Umble, M. (2003). Enterprise resource planning: Implementation procedures and critical success factors. European Journal of Operational Research, 146(2), 241257.

19. Verville, J., Bernadas, C. \& Halingten, A. (2002). So you're thinking of buying an ERP? Ten critical factors for successful acquisitions. Journal of Enterprise Information Management, 18(5/6), 665-677.

20. Verville, J. \& Halingten, A. (2002). An investigation of the decision process for selection and ERP software: the case of ESC. Management Decision, 40(3), 206-216. 